\title{
Kinetics of circulating Th17 cytokines and adipokines in psoriasis patients
}

\author{
Hideki Nakajima $\cdot$ Kimiko Nakajima $\cdot$ \\ Masahito Tarutani $\cdot$ Ryuji Morishige • \\ Shigetoshi Sano
}

Received: 2 March 2011/Revised: 23 May 2011/Accepted: 30 May 2011/Published online: 17 June 2011 (C) The Author(s) 2011. This article is published with open access at Springerlink.com

\begin{abstract}
Psoriasis is associated with an increase of Th17 cytokines, such as IL-17, IL-22, IL-21, and TNF- $\alpha$, which are produced by Th17 cells. Adipokines are peptide hormones or cytokines secreted from adipose tissues and involved in the pathogenesis of metabolic syndrome (MS). Psoriasis patients have a high prevalence of the MS. In this study, we investigated the statistics of circulating Th17-related cytokines and adipokines in psoriasis patients. Our study identified the significant elevation of serum IL-6, IL-21, IL-22, and resistin levels in psoriasis patients. Increased serum levels of IL-22 and adiponectin were positively correlated with Psoriasis Area and Severity Index (PASI). In contrast, serum high molecular weight adiponectin levels were decreased in psoriasis and negatively correlated with PASI.
\end{abstract}

Keywords IL-6 · IL-21 · IL-22 · Resistin · Adiponectin · HMW-adiponectin

\section{Introduction}

There has been a growing number of evidence that IL-17producing type 17, helper $\mathrm{T}$ (Th17) cells play an important role in the pathogenesis of psoriasis [8]. Th17 cells differentiate from naïve $\mathrm{CD} 4+\mathrm{T}$ cells under the stimulation of IL-1 $\beta$, IL-6, and IL-23, and their proliferation and

H. Nakajima $(\bowtie) \cdot$ K. Nakajima $\cdot$ M. Tarutani $\cdot$ S. Sano Department of Dermatology, Kochi Medical School,

Kochi University, Kohasu, Oko-cho, Nankoku 783-8505, Japan

e-mail: nakajima@kochi-u.ac.jp

R. Morishige

Scientific Affairs, Janssen Pharmaceutical K.K., 5-2,

Nishi-kanda 3-chome, Chiyoda-ku, Tokyo 101-0065, Japan maturation are further driven by IL-23. They can produce IL-17, IL-22, IL-21, and TNF- $\alpha$. IL-22 finally induces hyperplasia, abnormal differentiation and the expression of many antimicrobial peptides, such as S100 family proteins and $\beta$-defensin family proteins from keratinocytes [1].

Metabolic syndrome (MS) has been reported to be associated with an increased risk of psoriasis $[4,7,15]$. A recent study by Love et al. [7] demonstrated that the prevalence of MS was $40 \%$ among psoriasis patients, whereas $23 \%$ among the controls. Adipokines are cytokines derived from adipose tissues and involved in the pathogenesis of MS, however, the impact of adipokines on the psoriatic etiology remains unsolved. We previously demonstrated that serum levels of some adipokines, such as chemerin and leptin, were upregulated in psoriasis patients [9]. In this study, we investigated alternation of circulating cytokines (TNF- $\alpha$, IL-6, IL-17, IL-21, IL-22, and IL-23) and adipokines (retinol-binding protein-4: RBP-4, resistin, chemerin, and leptin; adiponectin and high molecular weight adiponectin: HMW adiponectin) in psoriasis patients, and their correlation with MS.

\section{Patients and methods}

All the procedures received approval from the Ethics Committee of Kochi Medical School, and all the subjects provided written informed consents. Fasting serum samples were obtained from psoriasis patients $(n=30)$, sex- and weight-matched control subjects $(n=30)$, and analyzed by enzyme-linked immunosorbent assay method (TNF- $\alpha$, IL-6, IL-17, IL-22, IL-23 and RBP4: R\&D Systems, Inc., MN. USA; IL-21: Bender Med Systems GmbH, Vienna, Austria, resistin: BioVendor, NC, USA; chemerin: Millipore Corporation, Billerica, MA, USA; leptin: B-Bridge 
International Inc., Mountain View, CA, USA; adiponectin and HMW adiponectin: Otsuka Pharmaceutical Co., Ltd., Tokyo, Japan). The serum chemistry and complete blood count tests were performed. Weight, height, body mass index (BMI), and waist circumferences of all the individuals were recorded. Disease severity was assessed with the Psoriasis Area and Severity Index (PASI) by the same physician.

\section{Results}

Patients with psoriasis presented higher levels of serum TNF- $\alpha$, IL-6, IL-21, IL-22, resistin, RBP-4, chemerin, and leptin (Table 1). Circulating IL-17 and IL-23 levels were below the detectable limits in both the groups in our experimental settings. Serum IL-6, IL-21, IL-22, resistin, chemerin and leptin levels were significantly elevated in patients with psoriasis when compared with the controls. On the other hand, serum TNF- $\alpha$ and RBP-4 levels were not significantly different. In contrast to the previous studies, total adiponectin levels in patients with psoriasis were not significantly different from the controls. However, HMW adiponectin levels were significantly lower in psoriasis patients when compared with those in controls (Table 1). Serum IL-21 level in the patients was not positively correlated with PASI score (Fig. 1a). However, we observed a positive correlation between IL-22 and PASI score (Fig. 1b). Serum levels of TNF- $\alpha$ (Fig. 1c), resistin (Fig. 2a, b) and RBP-4 levels (Fig. 2c, d) were not positively correlated with PASI score or BMI in psoriasis patients. Furthermore, serum resistin and RBP-4 levels were not different between the patients with and without hyperglycemia (data not shown). Serum total adiponectin levels were positively correlated with PASI score (Fig. 2e), and showed slightly negative correlation with BMI in patients with psoriasis (Fig. 2f). On the other hand, HMW adiponectin levels were negatively correlated with PASI score and BMI in psoriasis patients $(r=-0.296$ and $r=-0.267$ ). HMW adiponectin levels were also negatively correlated with BMI in the controls $(r=-0.230)$. A positive correlation between waist circumferences and serum levels of resisitin, RBP-4 and leptin was found in psoriasis patients and controls. Serum levels of total adiponectin and HMW adiponectin were negatively correlated with the waist circumferences in psoriasis patients and controls.

\section{Discussion}

Our study indicated that patients with psoriasis showed higher IL-22 levels than the controls, and that IL-22 values positively correlated with PASI score, in accordance with the previous report [19]. This result suggested that serum IL-22 was a good marker of the clinical severity of psoriasis. No detectable serum levels of IL-17 or IL-23 were found in both the groups. There are possibilities that such cytokines might be involved in the very early phase of psoriasis development or be present only in the lesional skin [10]. TNF- $\alpha$ levels were negatively correlated to the PASI, inconsistent with the results of Takahashi et al. [18].

Table 1 Serum levels of Th17-related cytokines and adipokines

\begin{tabular}{lllc}
\hline & Controls $(n=30)$ & Psoriasis patients $(n=30)$ & $p$ value \\
\hline TNF- $\alpha(\mathrm{pg} / \mathrm{ml})$ & $3.95 \pm 0.48$ & $17.80 \pm 12.50$ & 0.364 \\
IL-6 $(\mathrm{pg} / \mathrm{ml})$ & $2.85 \pm 0.50$ & $13.38 \pm 4.67$ & $<0.0001^{* *}$ \\
IL-17 $(\mathrm{pg} / \mathrm{ml})$ & $\mathrm{UD}$ & $\mathrm{UD}$ & $0.031^{*}$ \\
$\mathrm{IL}-21(\mathrm{pg} / \mathrm{ml})$ & $\mathrm{UD}$ & $32.7 \pm 18.01$ & $0.006^{* *}$ \\
IL-22 $(\mathrm{pg} / \mathrm{ml})$ & $2.50 \pm 0.66$ & $24.14 \pm 12.74$ & $0.022^{*}$ \\
IL-23 $(\mathrm{pg} / \mathrm{ml})$ & $\mathrm{UD}$ & $\mathrm{UD}$ & 0.079 \\
Resistin $(\mathrm{ng} / \mathrm{ml})$ & $3.44 \pm 0.37$ & $5.44 \pm 0.58$ & $31.69 \pm 3.82$ \\
RBP-4 $(\mathrm{ng} / \mathrm{ml})$ & $23.31 \pm 1.95$ & $188.05 \pm 7.78$ & $0.0001^{* *}$ \\
Chemerin $(\mathrm{ng} / \mathrm{ml})$ & $120.79 \pm 6.40$ & $22.84 \pm 3.55$ & $0.005^{* *}$ \\
Leptin $(\mathrm{ng} / \mathrm{ml})$ & $9.58 \pm 1.72$ & $9.46 \pm 1.03$ & 0.261 \\
Adiponectin $(\mu \mathrm{g} / \mathrm{ml})$ & $8.49 \pm 1.19$ & $3.58 \pm 0.37$ & $0.001^{* *}$ \\
HMW-adiponectin $(\mu \mathrm{g} / \mathrm{ml})$ & $6.31 \pm 0.66$ &
\end{tabular}

Serum IL-6, IL-21, IL-22, resistin, chemerin and leptin levels were significantly higher in psoriasis patients $(n=30)$ when compared with the controls $(n=30)$. Serum HMW adiponectin levels were significantly lower in psoriasis patients when compared with the controls. Values represent the mean \pm SEM. Statistical analysis was generated with Mann-Whitney test: * $p \leq 0.05$ and $* * p \leq 0.01$

$U D$ under the detection limit 

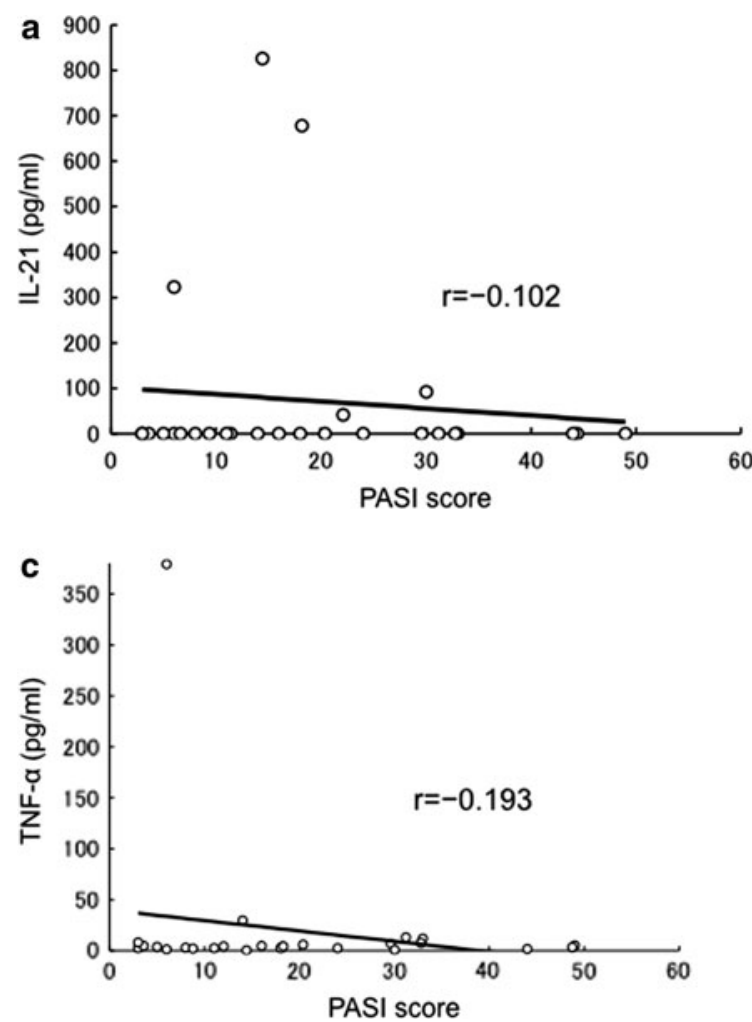

Fig. 1 Correlation between serum levels of cytokines and PASI score in psoriasis patients. Serum IL-21 levels did not positively correlate with PASI score in psoriasis patients (a). Serum IL-22 levels

The main reason for this discrepancy is due to relatively low levels of serum TNF- $\alpha$ in most of the psoriasis patients except for one patient with extremely high TNF- $\alpha$ values $(379 \mathrm{pg} / \mathrm{ml})$. On the other hand, a positive correlation was found between serum TNF- $\alpha$ levels and PASI $(r=0.179)$, when we limited to mild psoriasis patients (PASI score $\leq 10)$. We found a significant elevation of serum IL-21 and resistin levels in patients with psoriasis as compared to the controls.

Resistin was originally discovered in mouse adipocytes and assigned a role in the induction of murine insulin resistance [16]. Furthermore, it was reported that resistin stimulated the activation of macrophages to promote the secretion of proinflammatory cytokines [14]. Our finding in resistin confirms the pattern observed in a previous study [5]. There was no significant difference in RBP-4 levels between patients and controls, consistent with the result by Rollman et al. [12]. Microarray studies found high levels of RBP-4 expression in the adipose tissue of insulin-resistant glucose transporter 4 (Glut4) knockout mouse [20]. Recent studies have shown that serum RBP-4 levels were elevated in diabetes and obesity, whereas relationship between RBP-4 and insulin resistance still remains controversial [21]. Our results showed that there was no significant

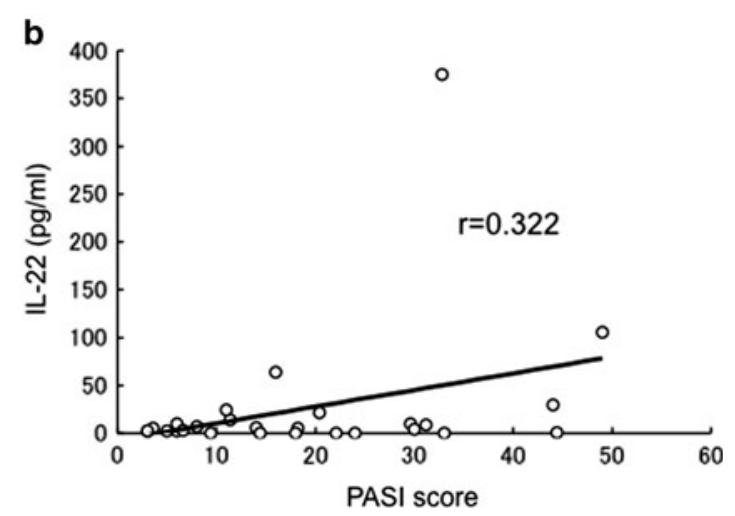

positively correlate with PASI score in psoriasis patients (b). Serum TNF- $\alpha$ levels did not positively correlate with PASI score in psoriasis patients (c)

correlation between hyperglycemia and levels of RBP-4 in psoriasis patients.

Total adiponectin levels did not differ significantly between psoriasis patients and controls in this study. Adiponectin possesses insulin-sensitizing and anti-inflammatory effects. Several studies have demonstrated that adiponectin was decreased in psoriasis [13, 17]. A study reported that serum adiponectin levels in normal-weight psoriasis patients were rather increased as compared to the healthy controls [6], which was consistent with our result. On the contrary, HMW adiponectin levels were significantly lower in our psoriasis patients as reported by Shibata et al. [13]. Our study indicated slightly negative correlation between total adiponectin and BMI in psoriasis. In addition, serum levels of HMW adiponectin were negatively correlated with BMI in psoriasis patients. Circulating adiponectin is decreased in obesity and diabetes, and it negatively correlates BMI [11]. Adiponectin levels were positively associated with PASI in our study, in contrast to the previous reports $[2,15]$. However, we found a negative correlation between serum high MW adiponectin levels and PASI. HMW adiponectin is suggested to be a more useful and sensitive marker for obesity and clinical severity in psoriasis. Although there was no negative correlation 
a

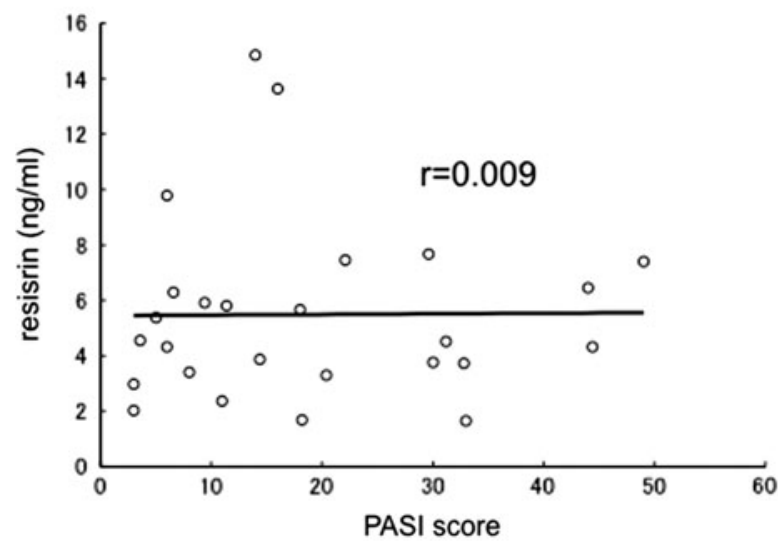

C

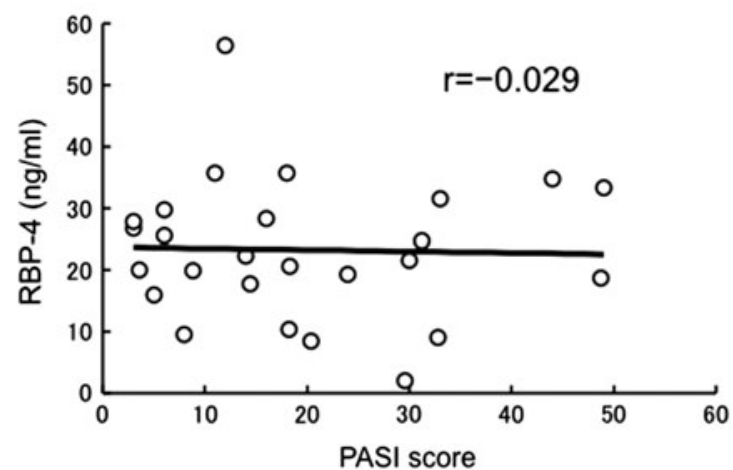

e

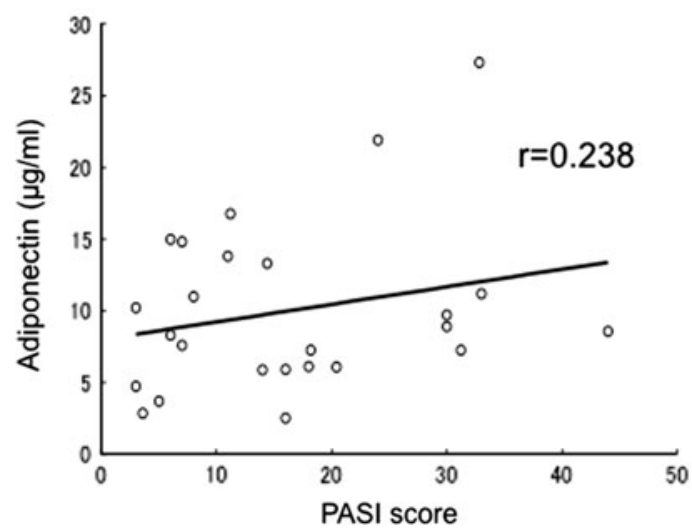

Fig. 2 Correlation between serum adipokine levels, PASI score, and BMI in psoriasis patients. Serum resistin levels did not positively correlate with PASI score (a). Correlation between serum levels of resistin and BMI in psoriasis patients (open circle), and normal controls (open triangle) (b). Serum resistin levels positively correlate with BMI in normal controls, although there was no positive correlation with BMI in psoriasis patients. Serum RBP-4 levels did

between serum total adiponectin levels and IL-6 levels $(r=0.017)$, a slightly negative correlation was found $(r=-0.069)$ between serum HMW adiponectin levels and IL-6 levels. Interestingly, a strong positive correlation was

\section{b}

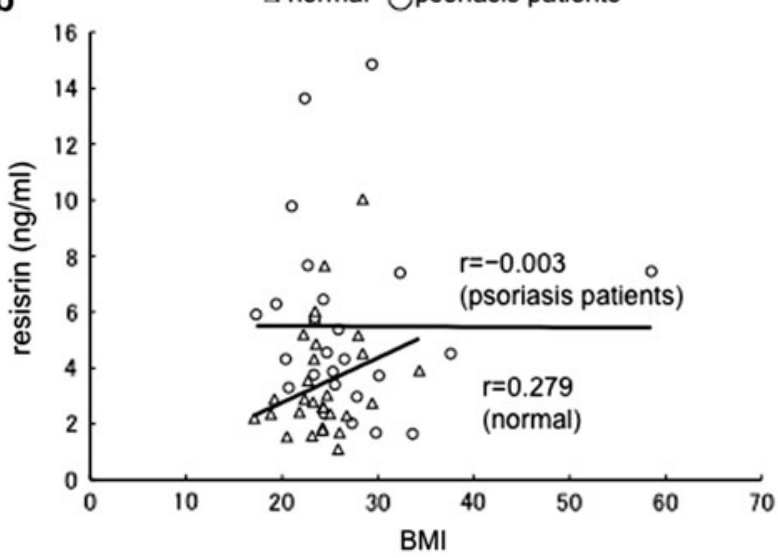

d $\Delta$ normal $\bigcirc$ psoriasis patients
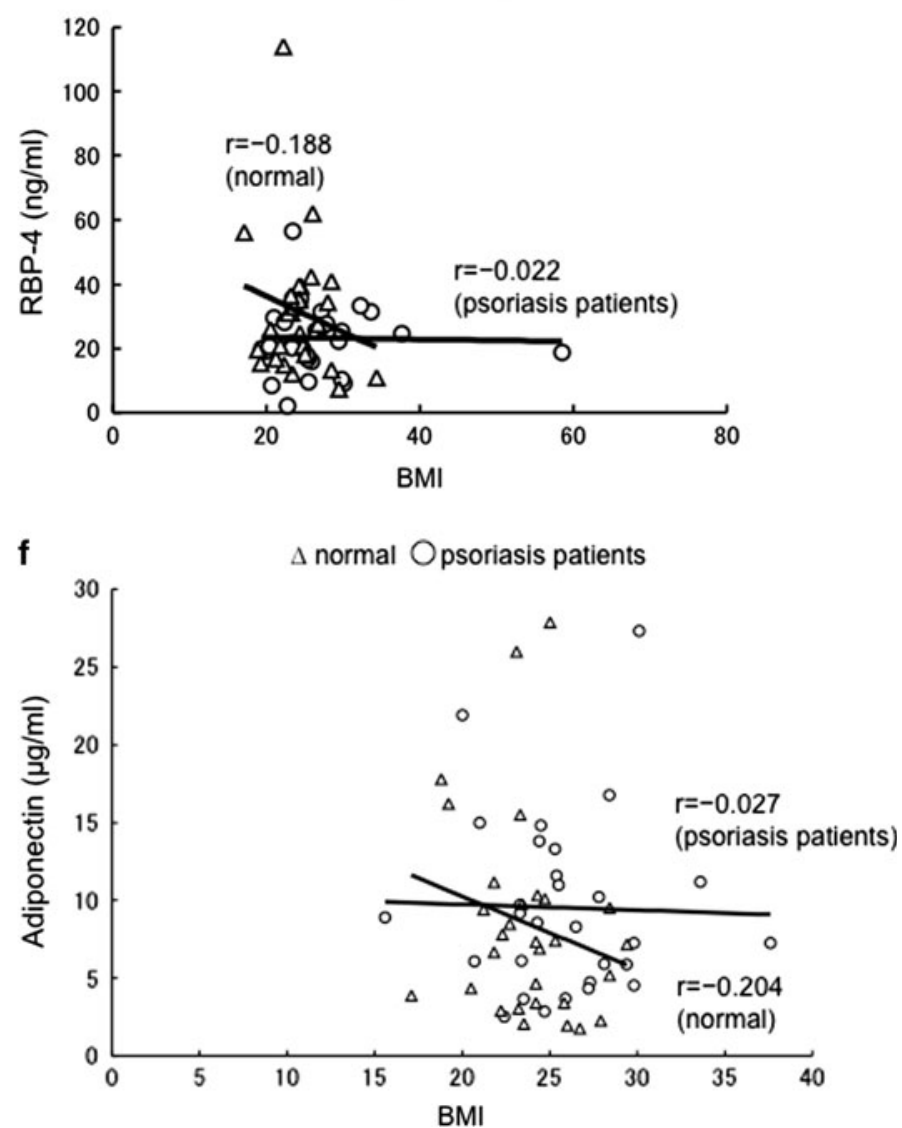

not positively correlate with PASI score $(\mathbf{c})$. There was no positive correlation between RBP-4 levels and BMI in psoriasis patients (d). Serum adiponectin levels positively correlated with PASI score in psoriasis patients (e). Serum adiponectin levels negatively correlate with BMI in normal controls, although there was slightly negative correlation in psoriasis patients (f)

found between serum total adiponectin levels and IL-6 levels $(r=0.6397)$, when we limited to moderate to severe psoriasis patients (PASI score $\geq 10$ ). These results showed that the properties of HMW adiponectin and total 
adiponectin in our psoriasis patients were different. It may be speculated that low and medium MW adiponectin productions are upregulated and that they do not have antiinflammatory effects in our psoriasis patients. Gerdes et al. [3] reported that increased levels of adiponectin were found in autoimmune and chronic inflammatory diseases, such as rheumatoid arthritis, systemic lupus erythematosus and inflammatory bowel disease, which were unrelated to increased adiposity. Total adiponectins other than HMW adiponectin may be upregulated in chronic inflammatory conditions.

In summary, serum IL-21, IL-22 and resistin levels were significantly elevated in psoriasis patients. Our findings suggested that serum IL-22 levels were correlated with clinical severity in patients with psoriasis. Serum adiponectin levels were positively related to PASI score. In contrast, serum HMW adiponectin levels were decreased in psoriasis patients and negatively correlated with PASI. It is possible that the biological effect of adiponectin could be dissected based on its molecular weight.

Acknowledgments This work was supported by a grant from Janssen Pharmaceutical K.K.

Conflict of interest The authors have no conflict of interest to declare.

Open Access This article is distributed under the terms of the Creative Commons Attribution Noncommercial License which permits any noncommercial use, distribution, and reproduction in any medium, provided the original author(s) and source are credited.

\section{References}

1. Boniface K, Bernard FX, Garcia M, Gurney AL, Lecron JC, Morel F (2005) IL-22 inhibits epidermal differentiation and induces proinflammatory gene expression and migration of human keratinocytes. J Immunol 174:3695-3702

2. Coimbra S, Oliveira H, Reis F, Belo L, Rocha S, Quintanilha A, Figueiredo A, Teixeira F, Castro E, Rocha-Pereira P, SantosSilva A (2010) Circulating adiponectin levels in Portuguese patients with psoriasis vulgaris according to body mass index, severity and therapy. J Eur Acad Dermatol Venereol 24:1386-1394

3. Gerdes S, Rostami-Yanzdi M, Mrowietz U (2011) Adipokines and psoriasis. Exp Dermatol 20:81-87

4. Gisondi P, Tessari G, Conti A, Piaserico S, Schianchi S, Peserico A, Giannetti A, Girolomoni G (2007) Prevalence of metabolic syndrome in patients with psoriasis: a hospital-based case-control study. Br J Dermatol 157:68-73

5. Johnston A, Arnadottir S, Gudjonsson JE, Aphale A, Sigmarsdottir AA, Gunnarsson SI, Steinsson JT, Elder JT, Valdimarsson $\mathrm{H}$ (2008) Obesity in psoriasis: leptin and resistin as mediators of cutaneous inflammation. Br J Dermatol 159:342-350
6. Kaur S, Zilmer K, Kairane C, Kals M, Zilmer M (2008) Clear differences in adiponectin level and glutathione redox status revealed in obese and normal weight patients with psoriasis. Br J Dermatol 159:1364-1367

7. Love TJ, Qureshi AA, Karlson EW, Gelfand JM, Choi HK (2011) Prevalence of the metabolic syndrome in psoriasis. Arch Dermatol 147:419-424

8. Lowes MA, Kikuchi T, Fuentes-Duculan J, Cardinal I, Zaba LC, Haider AS, Bowman EP, Krueger JG (2008) Psoriasis vulgaris lesions contain discrete populations of Th1 and Th17 T cells. J Invest Dermatol 128:1207-1211

9. Nakajima H, Nakajima K, Nagano Y, Yamamoto M, Tarutani M, Takahashi M, Takahashi Y, Sano S (2010) Circulating level of chemerin is upregulated in psoriasis. J Dermatol Sci 60:45-47

10. Nakajima K, Kanda T, Takaishi M, Shiga T, Miyoshi K, Nakajima H, Kamijima R, Tarutani M, Benson JM, Ellosso MM, Gutshall LL, Naso MF, Iwakura Y, Digiovanni L, Sano S (2011) Distinct roles of IL-23 and IL-17 in the development of psoriasislike lesions in a mouse model. J Immunol 186:4481-4489

11. Ouchi N, Walsh K (2007) Adiponectin as an anti-inflammatory factor. Clin Chim Acta 380:24-30

12. Rollman O, Vahlquist A (1985) Psoriasis and Vitamin A. Plasma transport and skin content of retinol, dehydroretinol and carotenoids in adult patients versus healthy controls. Arch Dermatol Res 278:17-24

13. Shibata S, Saeki H, Tada Y, Karakawa M, Komine M, Tamaki K (2009) Serum high molecular weight adiponectin levels are decreased in psoriasis patients. J Dermatol Sci 55:62-63

14. Silswal N, Singh AK, Aruna B, Mukhopadhyay S, Ghosh S, Ehtesham NZ (2005) Human resistin stimulates the pro-inflammatory cytokines TNF- $\alpha$ and IL- 12 in macrophages by NF- $\kappa$ Bdependent pathway. Biochem Biophys Res Commun 334:10921101

15. Sommer DM, Jenisch S, Suchan M, Christophers E, Weichenthal $M$ (2006) Increased prevalence of the metabolic syndrome in patients with moderate to severe psoriasis. Arch Dermatol Res 298:321-328

16. Steppan CM, Bailey ST, Bhat S, Brown EJ, Banerjee RR, Wright CM, Patel HR, Ahima RS, Lazar MA (2001) The hormone resistin links obesity to diabetes. Nature 409:307-312

17. Takahashi H, Tsuji H, Takahashi I, Hashimoto Y, Ishida-Yamamoto A, Izuka H (2008) Plasma adiponectin and leptin levels in Japanese patients with psoriasis. Br J Dermatol 159:1207-1208

18. Takahashi H, Tsuji H, Hashimoto Y, Ishida-Yamamoto A, Iizuka $\mathrm{H}$ (2009) Serum cytokine and growth factor levels in Japanese patients with psoriasis. Clin Exp Dermatol 35:645-649

19. Wolk K, Witte E, Wallace E, Döcke W-D, Kunz S, Asadullah K, Volk H-D, Sterry W, Sabat R (2006) IL-22 regulates the expression of genes responsible for antimicrobial defense, cellular differentiation, and mobility in keratinocytes: a potential role in psoriasis. Eur J Immunol 36:1309-1323

20. Yang Q, Graham TE, Mody N, Preitner F, Peroni OD, Zabolotny JM, Kotani K, Quadro L, Kahn BB (2005) Serum retinol binding protein 4 contributes to insulin resistance in obesity and type 2 diabetes. Nature 436:356-362

21. Yao-Borengasser A, Varma V, Bodles AM, Rasouli N, Phanavanh B, Lee MJ, Starks T, Kern LM, Spencer HJ 3rd, Rashidi AA, McGehee RE Jr, Fried SK, Kern PA (2007) Retinol binding protein 4 expression in humans: relationship to insulin resistance, inflammation, and response to pioglitazone. J Clin Endocrinol Metab 92:2590-2597 